\title{
Pyrometamorphism and partial melting of shales during combustion metamorphism: mineralogical, textural, and chemical effects *
}

\author{
Bryan H. Clark** and Donald R. Peacor \\ Department of Geological Sciences, The University of Michigan, Ann Arbor, MI 48109, USA
}

Received November 29, 1992 / Accepted August 18, 1992

\begin{abstract}
Eocene shales metamorphosed by a naturally ignited coal seam in the Powder River Basin, Wyoming record a continuum of mineralogic and textural changes from relatively unaltered shale to melt developed during pyrometamorphism. Samples collected along a section $2 \mathrm{~m}$ in length, corresponding to a temperature range of approximately $1300^{\circ} \mathrm{C}$, were examined optically and by XRD, SEM, and STEM. The low temperature samples are comprised primarily of silt-sized quartz, K-feldspar, and minor amounts of other detrital minerals in a continuous matrix of illite/smectite (I/S). Delamination of phyllosilicates due to dehydroxylation occurs early in the sequence with curling of individual layers from rim to core. Within one-half meter of melted areas, phyllosilicates have undergone an essentially isochemical reconstitution with nucleation and growth of mullite crystals with maximum diameters of $50 \mathrm{~nm}$, randomly distributed within a non-crystalline phase that replaces $\mathrm{I} / \mathrm{S}$. Large detrital grains remain for the most part unaffected except for the inversion of quartz to tridymite/cristobalite. Within $1 \mathrm{~mm}$ of the solid/melt interface, the mullitebearing clay mineral matrix is essentially homogeneous in composition with obscure grain boundaries, caused by apparent homogenization of poorly crystalline material. This material is similar in composition to parent clays and acts as a matrix to angular, remnant tridymite/ cristobalite grains. Rounded, smaller silica grains have reaction rims with the non-crystalline matrix; K-feldspar is no longer present (apparently reacted with the matrix) and the matrix contains abundant pore space due to shrinkage upon dehydroxylation. As isolated pods of paralava (glass) or fractures are approached, $\mathrm{Fe}-\mathrm{Ti}-$ Al oxides become abundant. Vesicular glass is separated from clinker by a well-defined interface and contains numerous phenocrysts. XRF analyses and reduced area
\end{abstract}

\footnotetext{
* Contribution No. 490, the Mineralogical Laboratory, Department of Geological Sciences, The University of Michigan

* Current address: Briggs Associates, Inc., 400 Hingham Street, P.O. Box 369, Rockland, MA 02370-0369

Correspondence to: B.H. Clark
}

rastering using EDS imply enrichment of the melt phase in $\mathrm{Fe}, \mathrm{Ca}, \mathrm{Mg}$ and $\mathrm{Mn}$, apparently due to vapor transport from other layers lower in the sedimentary sequence.

\section{Introduction}

Combustion metamorphism is a special case of pyrometamorphism in which thermal energy is provided through the burning of a buried coal seam. Examples have been reported from Australia, Israel, and over a broad range of the western United States from Montana south through Texas (Allen 1874; Bastin 1905; Baker 1953; Whitworth 1958; Matthews and Gross 1980; Herring 1980; Bentor et al. 1981; Hooper 1982; Cosca et al. 1989). Baking of associated sediments results in a striking change in color from tan to orange or red accompanied by an increase in fissility. Extensive cracking may also occur due to a loss of volatiles, principally $\mathrm{H}_{2} \mathrm{O}$. Such rocks are known as "burnt rocks" or "clinker" (Cosca et al. 1989). Temperatures may be high enough locally to promote melting of material directly in contact with the burning coal. Melting may also occur in the overlying sediments that are associated generally with "chimneys" through which heated gases rose. In this case, the melt may take the form of rounded pods that appear to be surrounded entirely by clinker. The solidified melt resembles igneous rocks in most respects and is known as "paralava."

Although clinker and paralava have been extensively documented since the first scientific descriptions by Allen (1874) and Rogers (1918), those descriptions primarily emphasized field relations. As the paralava may contain phenocrysts large enough for conventional observations, there have been numerous studies of the melt products of burnt rocks (e.g., Hooper 1982; Cosca and Essene 1985; Cosca et al. 1989). The associated pelitic sediments and equivalent clinker largely have been unstudied due in part to their small grain size. Scanning 


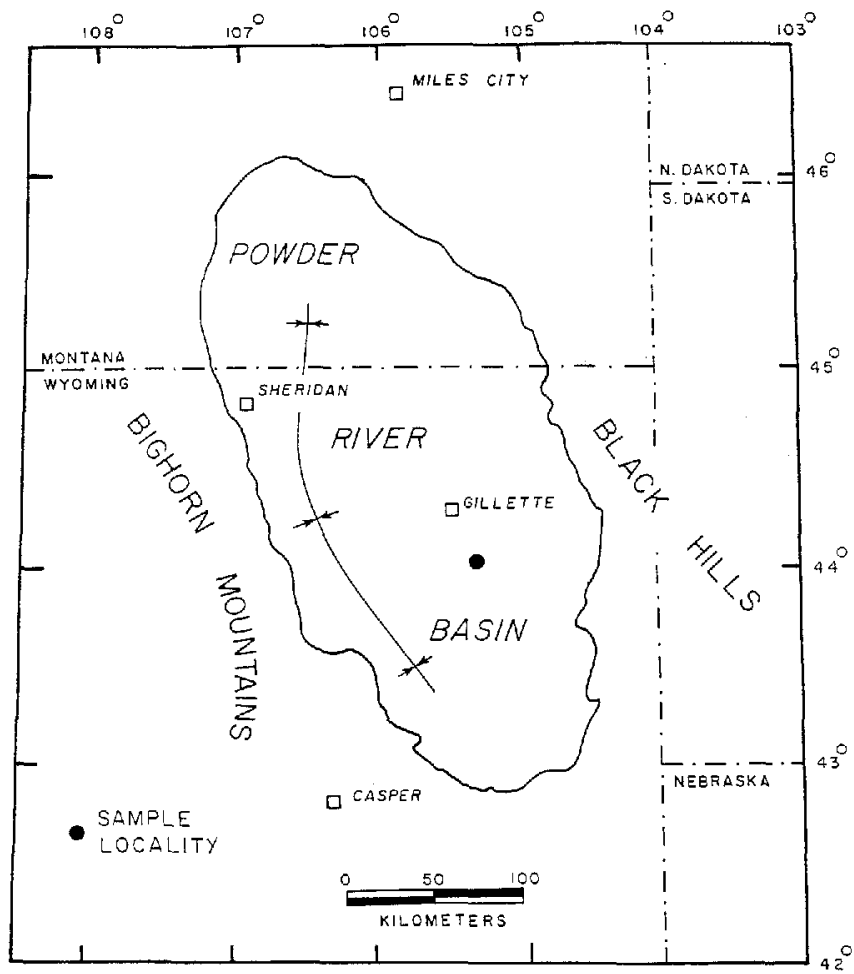

Fig. 1. Map of the Powder River Basin area after Cosca et al. (1989). Sample locality is marked as shown

electron microscopy (SEM) and scanning transmission electron microscopy (STEM) resolve the textures of these rocks and have been used to examine reactions in pelitic xenoliths (Grapes 1986; Brearley 1986, 1987) and alteration of phyllosilicates in contact aureoles (Smith 1969; Wirth 1985; Worden et al. 1987). However, those studies involved mineralogical changes that occurred at depth at lower temperatures, higher fluid pressures, and over a longer time period. Combustion metamorphism is a rapid, near-surface process that involves higher temperatures and near-anhydrous conditions (Cosca et al. 1989). This study was undertaken in order to detail the changes in mineralogy and texture of pyrometamorphosed pelitic sediments with special emphasis on reactions involving the fine-grained matrix minerals. It was prompted in part by the availability of a unique set of samples provided by M.A. Cosca and E.J. Essene.

\section{Sample description and preparation}

Samples collected for this study are from the Eocene Wasatch Formation of the Powder River Basin, Wyoming, (Fig. 1) which consists predominantly of quartz-rich siltstones and shales interlayered with coal seams and some horizons rich in ferruginous nodules. It many areas, the sediments have been baked by burning coal, resulting in clinker/paralava associations. The flat-lying beds are pierced by vertical chimncy structures which served as vents for escaping gases and heat. Surrounding these chimneys are contact aureoles around which rocks change continuously from apparently unaltered shale through various stages of alteration up to clinker and finally melt. At least three rock types are distinguishable on the basis of color: shale (representing the lowest temperature) is tan, clinker is red and paralava (representing the highest temperature) is dark red to black.

The five samples used in this study were collected in the contact metamorphic zone around a chimney along a horizontal traverse of two meters within the same bed. The samples are labeled KM1 through KM 5 corresponding to the lowest and highest temperature samples, respectively, and represent an approximatc temperature difference of $1300^{\circ} \mathrm{C}$ (Cosca et al. 1989). Samples KM1, KM2 and KM3 are tan in contrast to the red KM4 and KM5 clinker samples. Sample KM5 was nearest the chimney and contains cracks and pods of paralava completely enclosed by clinker.

\section{Sample analysis}

\section{$X$-ray fluorescence $(X R F)$}

Portions of samples KM1-5 and pods of paralava from within KM5 were ground separately in a tungsten carbide shatterbox. A large specimen of KM5 was sectioned into one inch thick slabs, and pods of paralava were carefully hand-picked from the clinker slabs to ensure that they were completely isolated and in no apparent way connected to other areas of paralava. A flux of lithium tetraborate was added to aliquots of the powdered samples, which were then fused into disks for major element analysis as specified by Norrish and Hutton (1969). Separate powder aliquots were pressed into pellets for trace element analysis. The XRF spectrometer used in this study was a Philips PW 1400 with a $3-\mathrm{kV}$ rhodium tube equipped with PET, TLAP, LIF 200, and LIF 220 crystals. A set of U.S. Geological Survey, C.R.P.G. (France), Japan Geological Survey and N.I.M. (South Africa) standard rocks were used in the calibration of XRF intensities. A modified Á-coefficient procedure of Norrish and Hutton (1969) was used to calculate matrix effects for major elements, and the major element compositions were used to calculate matrix effects for trace elements.

Results of the analyses (Table 1) indicate that despite their color differences, samples KM1-5 are approximately isochemical with respect to major and trace elements. The only exceptions appcar to be $\mathrm{Pb}$ (progressive loss upon heating) and $\mathrm{Ni}$ (higher concentration in KM1 than KM2-5). The loss on ignition (LOI) values show that volatiles, presumably largely $\mathrm{H}_{2} \mathrm{O}$, decrease markedly from sample KM3 to KM4. The SEM and TEM observations described below show that significant changes had occurred in phyllosilicates in sample KM3, assumedly (sce below) accompanied by at least partial dehydroxylation. The small LOI values for KM4, KM5, and the paralava thus apparently represent loss even of pore water in response to increasing temperature at low pressure. The low LOI values correspond to change in color from tan to red, indicating more oxidizing conditions that may correspond with dissociation of $\mathrm{H}_{2} \mathrm{O}$ (Cosca et al. 1989).

The composition of paralava pods, however, is markedly different from the clinker in which they are enclosed. Large increases in concentrations of $\mathrm{Fe}_{2} \mathrm{O}_{3}(1800 \%), \mathrm{CaO}(450 \%), \mathrm{MgO}(100 \%)$ and $\mathrm{MnO}(2500 \%)$ are coupled with smaller decreases in $\mathrm{SiO}_{2}$ $(50 \%), \mathrm{TiO}_{2}(50 \%), \mathrm{Al}_{2} \mathrm{O}_{3}(50 \%)$ and $\mathrm{K}_{2} \mathrm{O}(70 \%)$. Significant differences in the trace elements are also evident: increases in $\mathrm{Y}$, $\mathrm{Zn}, \mathrm{U}, \mathrm{Ni}, \mathrm{Sc}$ and $\mathrm{Ba}$; decreases in $\mathrm{Nb}, \mathrm{Th}, \mathrm{Rb}$ and $\mathrm{Nd}$.

\section{$X$-ray diffraction $(X R D)$}

Samples were ground using an agate mortar and pestle and applied as a slurry to glass slides for XRD analysis. Samples were scanned from $3-60^{\circ} 2 \theta$ with a step size of $0.01^{\circ}$ and counting time of $1 \mathrm{~s}$, using a Philips 3100 powder X-ray diffractometer system with graphite monochromator and $\mathrm{Cu}$ tube operated at $35 \mathrm{kV}$ and $15 \mathrm{~mA}$. Results are summarized in Table 2 . Silica polymorphs are ubiquitous in all five samples. The only $\mathrm{SiO}_{2}$ polymorph present in KM1-3 is quartz, but tridymite/cristobalite appear in KM4 and 
Table 1. XRF analyses of clinker and paralava

\begin{tabular}{|c|c|c|c|c|c|c|}
\hline & KM1 & $\mathrm{KM} 2$ & KM3 & KM4 & KM5 & Paralava \\
\hline $\mathrm{SiO}_{2}$ & 74.88 & 75.03 & 74.89 & 72.99 & 73.97 & 35.71 \\
\hline $\mathrm{TiO}_{2}$ & 0.86 & 0.88 & 0.87 & 0.87 & 0.85 & 0.46 \\
\hline $\mathrm{Al}_{2} \mathrm{O}_{3}$ & 18.64 & 18.89 & 18.55 & 19.64 & 18.16 & 9.58 \\
\hline $\mathrm{Fe}_{2} \mathrm{O}_{3}{ }^{\mathrm{a}}$ & 1.93 & 1.75 & 2.16 & 3.71 & 2.90 & 45.70 \\
\hline $\mathrm{MnO}$ & 0.04 & 0.04 & 0.03 & 0.04 & 0.03 & 1.04 \\
\hline $\mathrm{MgO}$ & 0.85 & 0.86 & 0.81 & 0.93 & 0.77 & 1.77 \\
\hline $\mathrm{CaO}$ & 0.48 & 0.48 & 0.45 & 0.24 & 0.50 & 2.58 \\
\hline $\mathrm{Na}_{2} \mathrm{O}$ & 0.00 & 0.07 & 0.00 & 0.00 & 0.02 & 0.00 \\
\hline $\mathrm{K}_{2} \mathrm{O}$ & 2.12 & 2.13 & 2.16 & 1.90 & 2.08 & 0.64 \\
\hline $\mathrm{P}_{2} \mathrm{O}_{5}$ & 0.12 & 0.08 & 0.07 & 0.10 & 0.10 & 0.24 \\
\hline Total & 99.92 & 100.21 & 99.99 & 100.46 & 99.39 & 97.72 \\
\hline $\mathrm{LOI}^{b}$ & 7.62 & 7.95 & 7.51 & 1.39 & 0.96 & 0.79 \\
\hline $\mathrm{Nb}$ & 16.7 & 16.0 & 16.9 & 17.6 & 16.0 & 9.2 \\
\hline $\mathrm{Zr}$ & 198.0 & 192.6 & 200.3 & 206.1 & 210.5 & 162.1 \\
\hline $\mathrm{Y}$ & 28.6 & 23.5 & 26.0 & 27.9 & 28.1 & 53.8 \\
\hline $\mathrm{Sr}$ & 136.6 & 113.7 & 118.6 & 95.1 & 123.3 & 116.3 \\
\hline Th & 15.8 & 15.7 & 14.0 & 16.1 & 14.1 & 9.8 \\
\hline $\mathrm{Pb}$ & 17.2 & 10.1 & 14.8 & 4.2 & 0.0 & 6.4 \\
\hline $\mathrm{Ga}$ & 19.9 & 17.9 & 17.3 & 19.5 & 17.1 & 16.8 \\
\hline $\mathrm{Zn}$ & 57.1 & 53.1 & 56.7 & 58.9 & 70.6 & 211.3 \\
\hline $\mathrm{Cu}$ & 9.7 & 14.1 & 12.6 & 14.7 & 21.1 & 0.0 \\
\hline $\mathrm{Ni}$ & 84.1 & 15.6 & 12.1 & 21.6 & 16.5 & 85.2 \\
\hline $\mathrm{U}$ & 8.5 & 8.4 & 4.9 & 7.9 & 6.3 & 13.1 \\
\hline $\mathrm{Rb}$ & 122.2 & 117.4 & 110.8 & 115.8 & 119.5 & 39.4 \\
\hline $\mathrm{Cr}$ & 93.8 & 95.0 & 97.3 & 101.5 & 92.9 & 60.6 \\
\hline $\mathrm{Ce}$ & 74.4 & 71.7 & 80.1 & 83.2 & 75.8 & 74.6 \\
\hline $\mathrm{Sc}$ & 10.6 & 10.6 & 15.0 & 12.2 & 7.7 & 31.7 \\
\hline $\mathrm{Nd}$ & 26.7 & 31.6 & 27.7 & 30.2 & 34.1 & 9.9 \\
\hline $\mathrm{Ba}$ & 618.3 & 599.8 & 583.0 & 508.9 & 549.1 & 983.8 \\
\hline V & 171.6 & 160.6 & 140.0 & 183.1 & 140.5 & 172.4 \\
\hline $\mathrm{La}$ & 39.4 & 48.7 & 47.7 & 48.1 & 38.9 & 38.8 \\
\hline
\end{tabular}

Oxides are given in wt \% and elements in ppm

a Total $\mathrm{Fe}$ reported as $\mathrm{Fe}_{2} \mathrm{O}_{3}$

${ }^{b} \mathrm{LOI}$, total loss of weight after drying the powder at $1100^{\circ} \mathrm{C}$ for $8 \mathrm{~h}$

Table 2. Phases identified by XRD analyses of clinker ${ }^{\mathrm{a}}$

\begin{tabular}{llllll}
\hline & KM1 & KM2 & KM3 & KM4 & KM5 \\
\hline Quartz & XX & XX & X & X & \\
Smectite/illite & XX & XX & X & & \\
Tridymite/cristobalite & & & & X & XX \\
Mullite & & & & & X \\
\hline
\end{tabular}

${ }^{a} \mathrm{XX}$, major phase; $\mathrm{X}$, minor phase

are the dominant polymorphs in KM5. A distinction between cristobalite and tridymite was not possible as peaks were broad and only peaks common to both phases were observed. The presence of such phases implies that samples KM4 and KM5 must have been heated (at least locally) to approximately $870^{\circ} \mathrm{C}$ (Deer et al. 1966). Clay minerals such as illite and smectite were detected only in $\mathrm{KM} 1, \mathrm{KM} 2$, and $\mathrm{KM} 3$, with smectite peaks becoming weaker and more diffuse in $\mathrm{KM} 2$ and especially in KM3. Mullite was detected only in KM5 by XRD. Least-squares refinement of mullite lattice parameters gave $a=0.7540(8), b=0.7689(7)$, and $c=$ $0.2890(2) \mathrm{nm}$. Comparison with the data of Cameron (1977) shows that it is the $3: 2$ variety $\left(3 \mathrm{Al}_{2} \mathrm{O}_{3}: 2 \mathrm{SiO}_{2}\right)$.

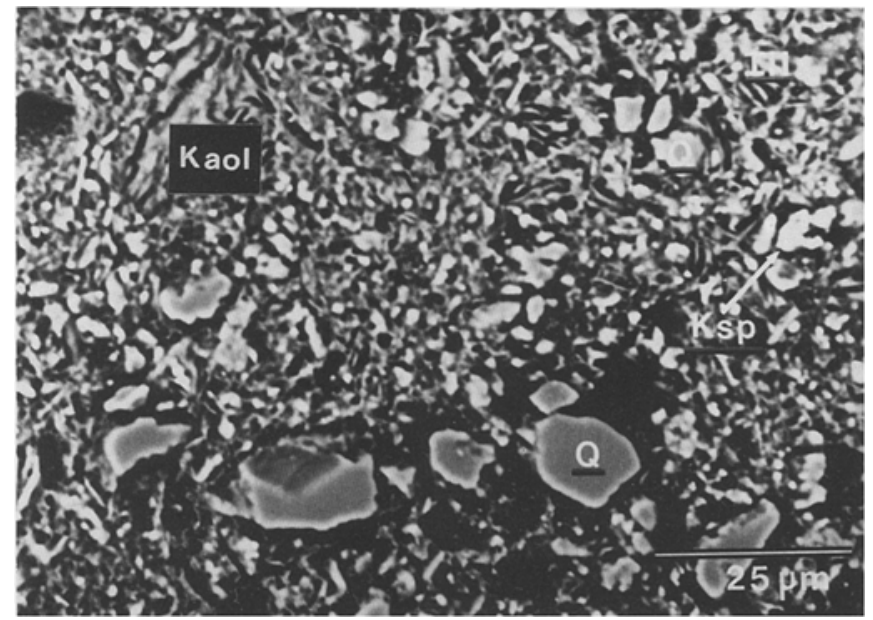

Fig. 2. BSE image of a low temperature sample. Angular detrital grains, primarily quartz, $Q$, but also potassium feldspar, $K s p$, and kaolinite, Kaol, are surrounded by a continuous matrix of illite/ smectite

\section{Microscopy}

Standard polished thin sections were prepared for all optical and scanning electron microscope (SEM) observations. For selected areas where there was a high likelihood of grains being plucked during polishing of thin sections, impregnated, polished chips were used. The STEM observations were made using ion-milled samples obtained from "sticky-wax"-backed thin sections.

Back-scattered electron (BSE) images obtained with the SEM, coupled with energy dispersive X-ray (EDX) analyses, provided medium-scale resolution and textural and chemical imaging, primarily of the non-clay minerals. Transmission electron microscopy coupled with analytical electron microscopy (AEM) was used to characterize the fine-grained material, especially the smaller claymineral domains. Detrital muscovite was identified as occurring in large, defect-free grains as a well-ordered two-layer polytype with nearly ideal $\mathrm{K} / \mathrm{Si}$ and $\mathrm{Al} / \mathrm{Si}$ ratios, whereas authigenic illite/ smectite (I/S) occurs in small, defect-rich grains as a $1 \mathrm{Md}$ polytype having smaller $\mathrm{K} / \mathrm{Si}$ and $\mathrm{A} 1 / \mathrm{Si}$ ratios.

\section{Low temperature samples}

Figure 2 is representative of the lowest temperature sample. Relatively large silt-sized grains are surrounded by a matrix of minerals that are too fine to be resolved by BSE imaging but that are shown by TEM to consist largely of clay minerals. The larger grains are primarily quartz. K-feldspar is also prominent, both as separate grains and with quartz in lithic fragments. Sub-angular detrital grains of muscovite, biotite, chlorite, kaolinite and pyrophyllite occur in grains up to $20 \mu \mathrm{m}$ in length.

Figure 3 is a low resolution TEM image of specimen KM1; I/S forms a continuous matrix around the larger detrital grains, primarily quartz. The anastomozing, wavy layers change orientation continuously across the area. Such textures are characteristic of an intermediate range of burial diagenesis (e.g. Lee et al. 1985). The XRD data show that the $1 / S$ has a significant smectite component which implies, by analogy with burial diagenetic sequences from the Gulf Coast (e.g. Hower et al. 


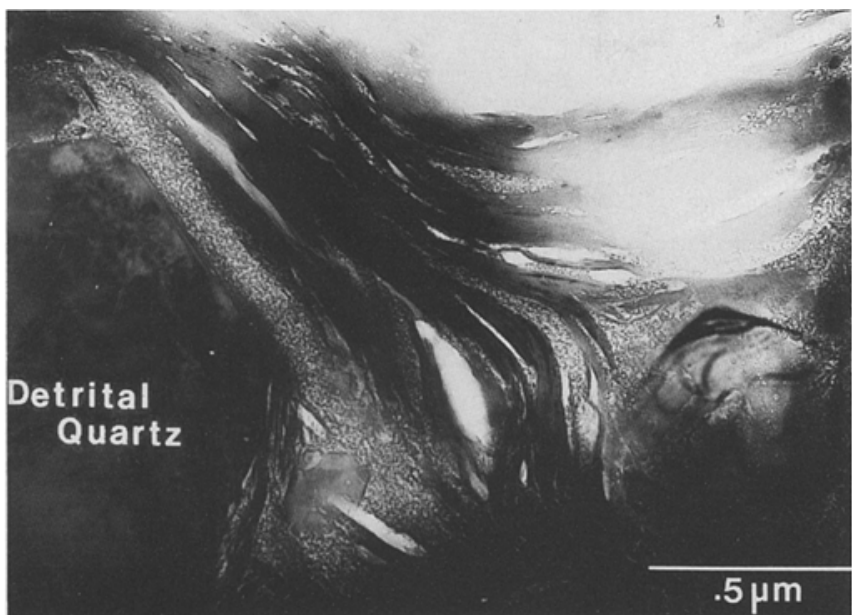

Fig. 3. TEM image of partially dehydroxylated illite/smectite forming a continuous matrix to detrital quartz grains
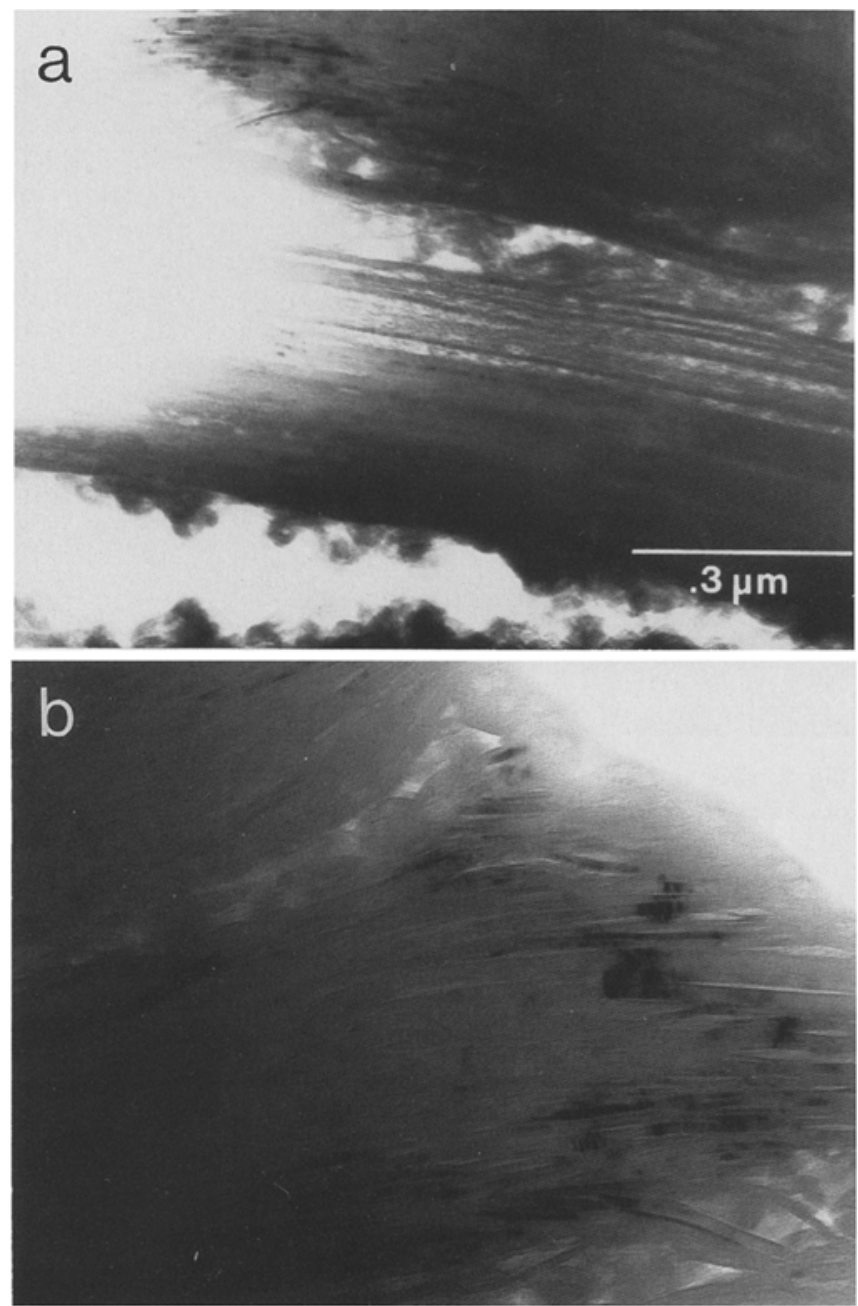

Fig. 4a, b. TEM images of partially dehydroxylated illite from sample KM2: a low resolution TEM image, layers have rolled in response to heating and $\mathrm{H}_{2} \mathrm{O}$ loss, creating additional pore space at an advancing front of alteration; $\boldsymbol{b}$ high resolution TEM image showing packets of illite layers, enlarged from a
1976), that the sediment has not been affected by burial temperatures much in excess of $100^{\circ} \mathrm{C}$. The retention of the original I/S over much of sample KM1 shows that it has not been significantly affected by the thermal metamorphism.

However, as shown in the TEM image, the I/S is locally changed as manifested in splitting along (001), with layers adjacent to the resulting void space rolled up or having a "crinkled" appearance. Some of the void space created by splitting of layers may be due to loss of interlayer $\mathrm{H}_{2} \mathrm{O}$ from smectite caused by the vacuum of the TEM. However, the damage in 001 layers is unique to these specimens relative to our experience with observations of hundreds of $\mathrm{I} / \mathrm{S}$ samples from a variety of environments, and largely must be a result of local $\mathrm{H}_{2} \mathrm{O}$ loss caused by heating of the original sample, and not an artifact of specimen preparation or observation. The I/S that displayed curling and "crinkling" of the layers gave no diffraction pattern using SAED, implying complete breakdown of structure.

Figures $4 a, b$ are high resolution images of an illite grain at an intermediate stage of alteration, as indicated by partial delamination. Figure 4 a shows a greater degree of delamination when compared to that shown in Fig. 3. In some areas, the layers are rolled into scroll-like features bounded on one side by apparently coherent illite, and on the other side by newly created void space. Figure $4 \mathrm{~b}$ is an enlargement of the area shown in Fig. $4 \mathrm{a}$, revealing the presence of lattice fringes. This indicates that some areas within this grain are still crystalline as opposed to the curled layers which do not produce observable peaks by electron diffraction. Rolling of layers is inferred to have resulted from stress caused by shrinkage concomitant with dehydroxylation. The dehydroxylation appears to advance layer-by-layer, leaving behind the melange of crinkled parts of layers in enlarged void space.

\section{Intermediate samples}

Figure 5 is a BSE image of specimen KM3. It retains the dominant textural features of the original sediment with detrital grains having outlines that appear to be unchanged. However, the silt-sized grains contain abundant and prominent cracks, presumably caused by stress induced by thermal expansion. The cracks are especially prominent in quartz. The fine-grained clay matrix appears to be more homogeneous, with unresolvable boundaries between small grains that were resolvable in specimens heated to lower temperatures. Delamination of large detrital phyllosilicate grains is apparent.

Figure 6 is a TEM image showing I/S in a more advanced state of reaction. Back-scattered electron imaging indicates that this clay matrix is homogeneous. It gives a diffraction pattern consistent with a 2:1 layer silicate, but the weakness and diffuseness of the reflections imply that it is only locally crystalline. The layered contrast occurring parallel to (001) is unique in appearance, with the dark bands having the width of approximately 10 layers but its cause is unknown. Crosscutting 


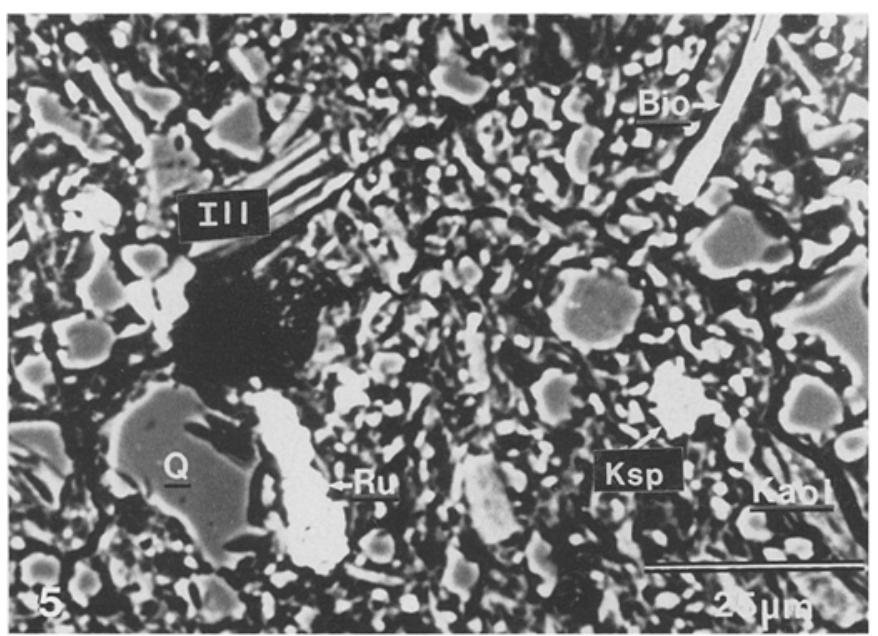

Fig. 5. BSE image of an intermediate temperature sample, KM3. Separation of layers in detrital phyllosilicates has occurred due to dehydroxylation. Ill, illite; $R u$, rutile; Bio, biotite; Kaol, kaolinite; $Q$, quartz; $K s p$, potassium feldspar

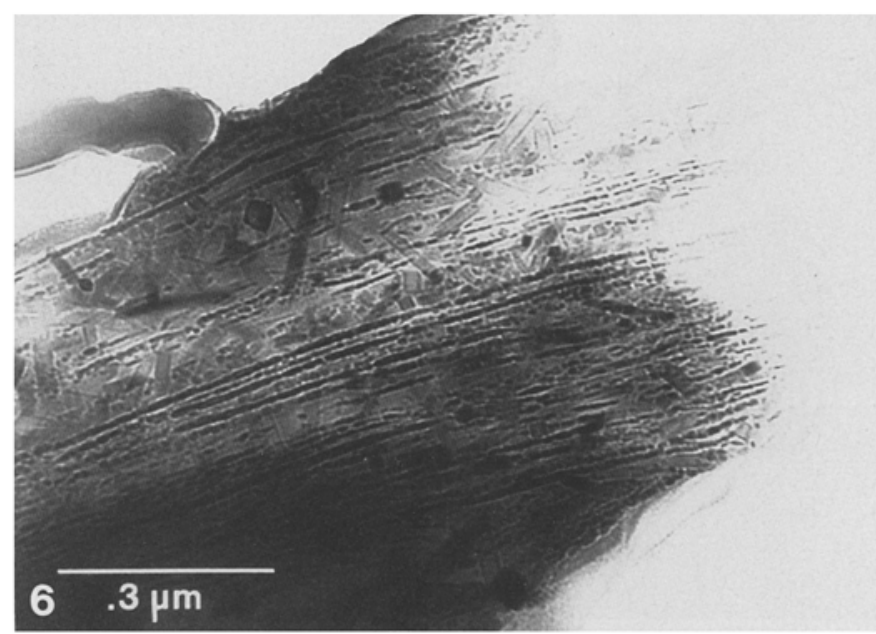

Fig. 6. TEM image (underfocused) of transformed illite containing mullite crystals which crosscut original 2:1 layering

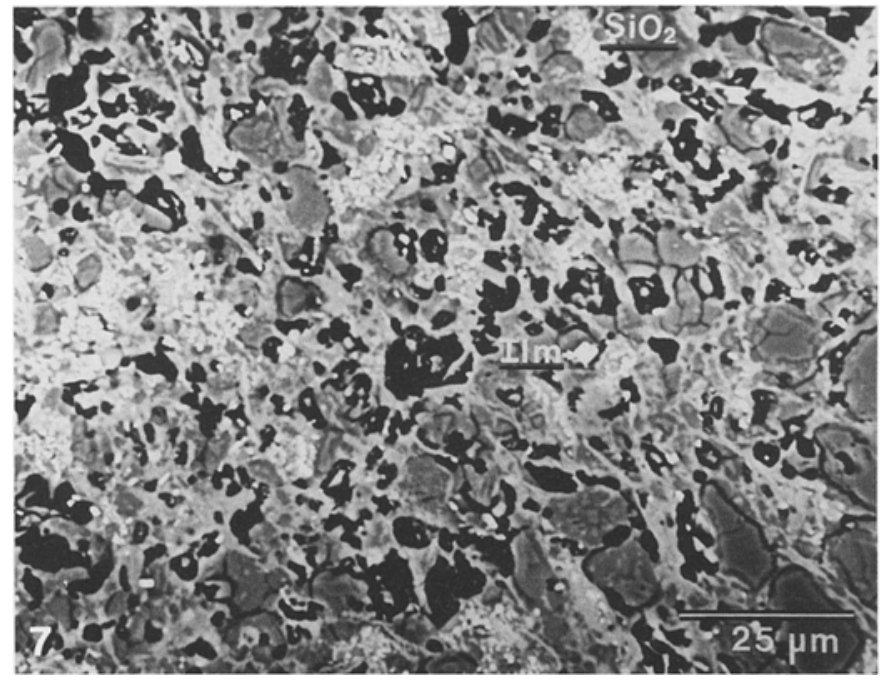

Fig. 7. BSE image of a sample near melt (KM4). The clay-rich matrix has begun to homogcnize, with production of pore space. Cracking of detrital silica grains is due to inversion of quartz to higher temperature polymorphs. Euhedral oxides such as ilmenite, IIm, are present

(001) are elongated crystals up to $0.5 \mu \mathrm{m}$ in length with square cross sections. These give single crystal diffraction patterns consistent with mullite, confirmed by qualitative EDS analysis and by the appearance of peaks for mullite in the XRD pattern of this specimen. The occurrence of such mullite crystals requires local diffusion of original elements in the clay mineral over distances of at least $50 \mathrm{~nm}$, with destruction of the 2:1 layers. The occurrence of characteristic $1 \mathrm{~nm} 001$ reflections in SAED patterns shows that some 2:1 layers remain ordered, and implies extreme heterogeneity on a local level.

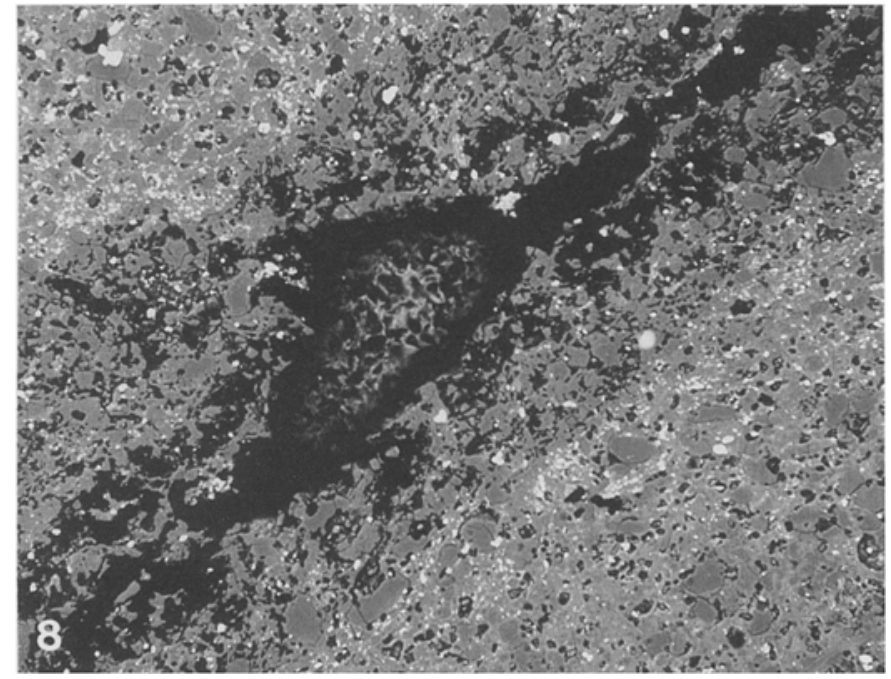

Fig. 8. BSE image of a crack within the clinker. The proportion of oxides increases as the crack is approached

\section{High temperature samples}

Specimen KM4 (Fig. 7) was collected only 20 to $30 \mathrm{~cm}$ from the paralava. On the basis of the presence of tridymite/cristobalite and the proximity to paralava, temperatures must have approached at least $1000^{\circ} \mathrm{C}$. Feldspar and silica grains are even more severely cracked than in previous samples. In the case of silica this probably results in part from the large volume change during inversion to higher temperature polymorphs. Delamination of large phyllosilicate grains is also apparent, giving 
rise to separation of some (001) layers. Such separations serve as the foci for major cracks running through the rock. Some of the silica grains have rims with contrast that is slightly different than that of the grain interiors. The SEM and STEM EDS analyses indicate the presence of some $\mathrm{Al}$, in addition to $\mathrm{Si}$, implying that there has been some reaction between detrital silica and matrix clays.

It is in the clay matrix that the major changes are observed. The large irregular areas with dark grey levels are pore space as indicated in part by their presence around detrital silica grains and rounded outlines. Porosity is interpreted to be the result of shrinkage caused by dehydroxylation of the original I/S clay matrix. Pore space is especially apparent around larger detrital grains, where it presumably results from the matrix pulling away from larger grains. Where larger voids exist, there is a remote possibility that void space is produced by plucking of grains during section preparation, but that cannot be the case where voids are associated with remnant detrital grains. Qualitative EDS analyses show that the matrix material contains $\mathrm{Si}$ and $\mathrm{Al}$ as the dominant elements, with minor $\mathrm{K}$ and $\mathrm{Fe}$, consistent with dehydroxylated I/S. The matrix is generally homogeneous in contrast in BSE images, consistent with a general homogenization in chemistry and structure.

Figure 8 is a BSE image showing the gradient from clinker to an open crack. Apparently there was no melt produced here, yet there is an increasing proportion of high atomic number minerals ( $\mathrm{Fe} / \mathrm{Ti}$ oxides) as the crack is approached. The pore space created by the shrinkage of the clay matrix (as seen in Fig. 7) partially has been filled by the subhedral oxides, which take on the shapes of the voids. The detrital silica grains are still evident in the matrix and even at the edges of the crack. This crack is interpreted as a conduit through which vapor escaped during the burning of the coal seam.

\section{Paralava}

A BSE image of the paralava is shown in Fig. 9. The pore space that was so prominent in the clinker is absent. The paralava consists in part of subhedral crystals inferred by Cosca et al. (1989) to have crystallized from a melt. Those crystals are included within a matrix of glass (see below) produced by rapid cooling of a melt. The crystalline phases include anorthite, $\mathrm{Fe}-\mathrm{Ti}-\mathrm{Al}$ spinels and cristobalite. In addition to single crystal phases, the spinels and cristobalite commonly occur as symplectic intergrowths. All crystalline phases were identified using optical techniques, EDS analyses, and SEM and TEM images.

The material enclosing crystalline phases such as anortbite is shown to be glass by the following data. Qualitative EDS analyses show that $\mathrm{Si}$ and $\mathrm{Al}$ are the dominant elements, but the composition varies continuously over wide limits. Minor elements such as $\mathrm{Fe}, \mathrm{Ti}, \mathrm{Mg}$, $\mathrm{K}$ and $\mathrm{Ca}$ are also present, but their proportions also vary from area to area. Optical observations show that this material is isotropic and no peaks were observed in SAED patterns. Rounded, hollow areas occur with diameters varying from less than $1 \mu \mathrm{m}$ continuously up to $3 \mathrm{~cm}$ as seen in hand specimen, frequently lined with hematite. These are interpreted as vesicles, in agreement with the conclusions of Cosca et al. (1989).

\section{Clinker-paralava interface}

Figure 10 is a BSE image that includes the contact between paralava (upper right) and clinker (lower left). The clinker that is furthest from the interface has the same features as seen in Fig. 7 (e.g., rounded, partially reacted, silt-sized grains in a homogeneous matrix of reacted clays marked by pore space created by shrinkage). However, the remaining detrital grains consist almost entirely of cristobalite as shown by SAED patterns of sample KM5. Figure 11 is an image of cristobalite showing stacking faults parallel to (111), with domains related by twinning. K-feldspar is absent; therefore it is inferred that $\mathrm{K}$-feldspar served, together with clay minerals, as a reactant to form the non-crystalline, altered clay matrix. Figure 12 is a STEM image of degraded clay matrix close to the boundary with the paralava. Prismatic mullite crystals are evident, and a square cross section is shown by one grain with dark contrast close to the Bragg condition. In other areas, the mullite crystals are present in much greater abundance, filling the field of view with randomly oriented crystals.

As the clinker/paralava interface is approached, grains of $\mathrm{Fe}-\mathrm{Ti}$ oxides (bright in BSE images) are more abundant (Fig. 10). They consist of magnetite and ulvospinel solid solutions as determined by optical properties and EDS data. In addition, hercynite and complex solid solutions of all three spinel components occur in increasing abundance. Such heterogeneity in spinel minerals clearly indicates a lack of chemical equilibrium. The oxides occur both as euhedral crystals and irregular, rounded grains up to $5 \mu \mathrm{m}$ in diameter. The STEM EDS analyses obtained in a traverse across the contact between a spinal grain and the matrix revealed no compositional gradient in $\mathrm{Fe}$ and $\mathrm{Ti}$; rather, a sharp increase in $\mathrm{Fe}$ and $\mathrm{Ti}$ concentrations occurred at the grain boundary.

Grain boundaries as seen in BEI are diffuse in the clinker but become well-defined in the crystalline paralava (Fig. 10). Grain boundaries between oxides and crystals of other minerals that are unique to the paralava tend to be irregular, implying that the oxides may be residual phases from the clinker. Furthermore, with increasing distance from the interface with clinker, fewer grains of the oxides are evident in paralava.

Qualitative EDS analyses of the matrix material of both clinker and paralava were obtained in order to determine the trends in changes in composition associated with melting. The specimen consisted of a domain of clinker having a red-orange color with paralava on two sides. Analyses were obtained using reduced area rasters of $20 \times 20 \mu \mathrm{m}$ along traverses across the interface. The traverse terminated in paralava at both ends. Care was taken to avoid all large detrital grains in the clinker 


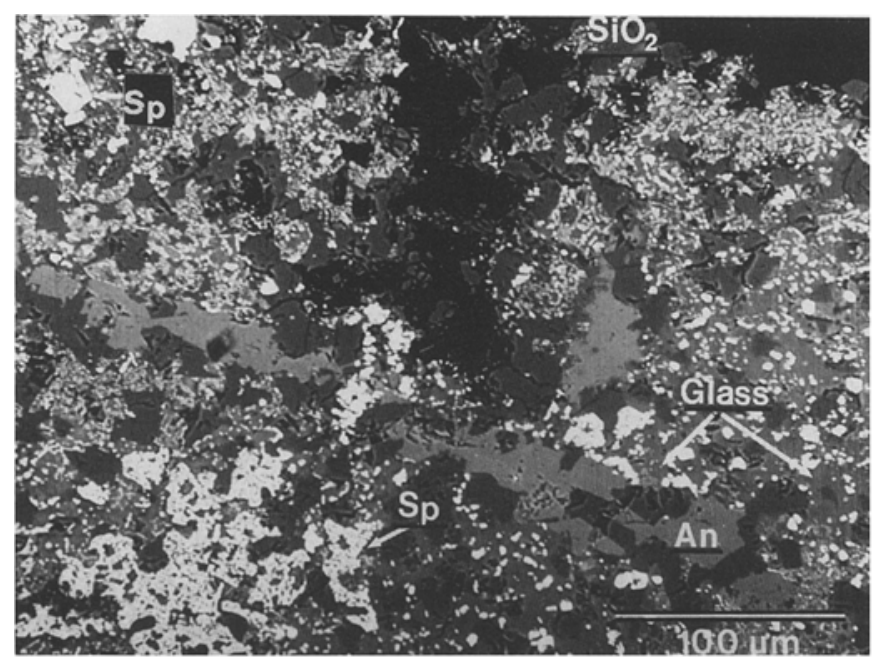

Fig. 9. BSE image of the paralava (KM5) containing glass, anorthite, iron-rich spinel symplectite, $S p$ and residual, detrital silica. Pore space is conspicuously absent. $A n$, anorthite

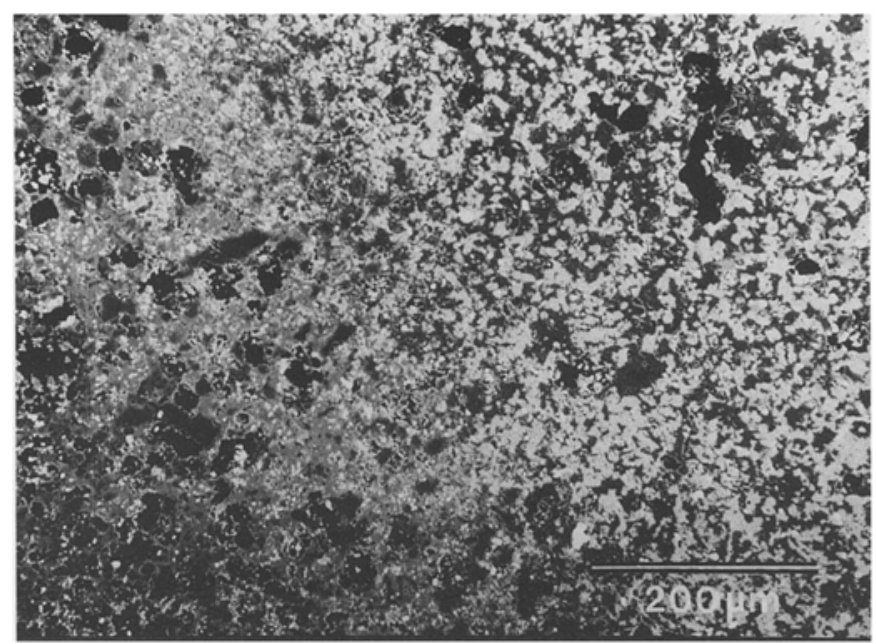

Fig. 10. BSE image of the clinker/paralava interface. Clinker is in the lower left corner and paralava is in the upper right. There is substantially less porc space in the paralava and a dramatic increase in high atomic number phases, mostly iron-aluminiumtitanium oxides

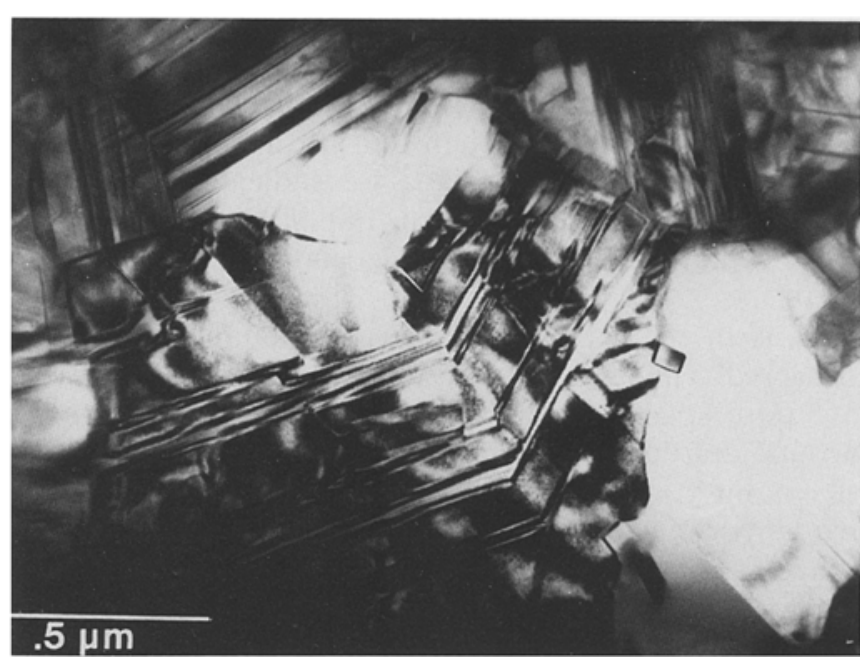

Fig. 11. TEM image of twinned cristobalite with numerous stacking faults as a transformation product of a detrital quartz grain

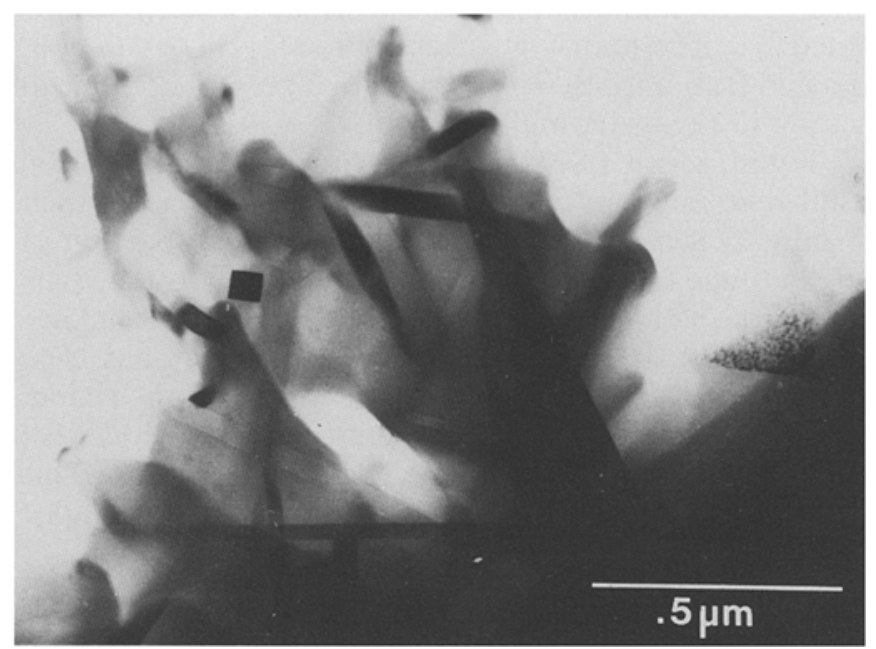

Fig. 12. TEM image of mullite crystals in a transformed, residual clay mineral matrix showing homogenization of original layered structure, sample KM5

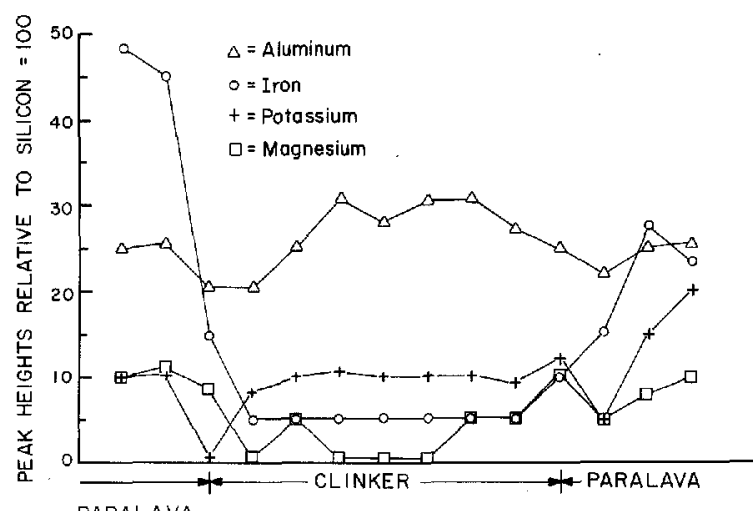

PARALAVA

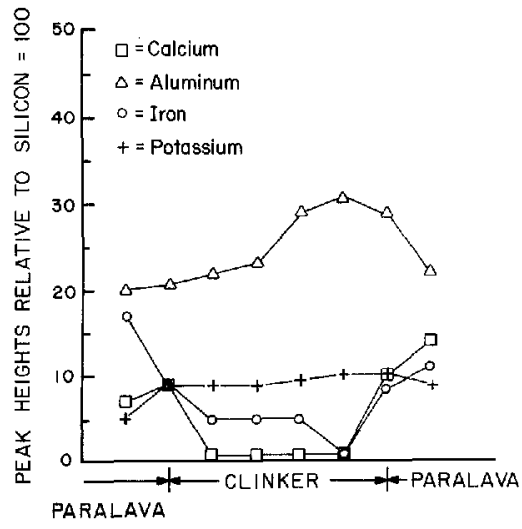

Fig. 13. Variation in composition across two clinker/paralava contacts. Each point represents a reduced area raster of $20 \times 20 \mu \mathrm{m}$ in a STEM EDS analysis 
and crystals in the paralava. Figure 13 demonstrates qualitative changes in composition as shown by values for peak heights for $\mathrm{K}$-emission lines of $\mathrm{Al}, \mathrm{K}, \mathrm{Ca}$, and $\mathrm{Fe}$ relative to that of $\mathrm{Si}$. There are significant increases in the proportions of $\mathrm{Fe}$ and $\mathrm{Ca}$ in the paralava, and slightly higher levels of $\mathrm{Al}$ and $\mathrm{K}$ in the clinker. These data are in agreement with the bulk XRF analyses.

The EDS analyses of the degraded clay within the clinker show very little variation from point to point in areas adjacent to the paralava contact, implying that homogenization had occurred relative to the variable analyses of the $\mathrm{I} / \mathrm{S}$ in samples distant from the paralava. On the other hand, the glass matrix of the paralava is relatively heterogeneous in composition.

\section{Discussion and conclusions}

\section{Summary of observations}

The temperature range for the five samples of this study is estimated to be approximately $1300^{\circ} \mathrm{C}$ based on the minimum melting temperature of the paralava (Cosca et al. 1989). This is probably a maximum sustained temperature for the clinker, but local hotspots at much higher temperatures are possible.

The most obvious macroscopic difference between the low temperature clinker samples and the high temperature samples is the color change from tan to red. This has been interpreted as an increase in the total $\mathrm{Fe}$ content in the clinker (Hooper 1982). This is not the case in the rocks of this study as bulk analyses by XRF show that the iron contents of the tan and the red clinker are essentially the same. Cosca et al. (1989) inferred that there are large $\mathrm{fO}_{2}$ differences over lateral distances of less than two meters. The color change is therefore most likely a result of differences in oxidation states.

The mineralogic and textural changes in clinker are confined to the phyllosilicate matrix material at low to moderate temperatures, with the large detrital grains remaining relatively unaffected until near-melt conditions. Initially the matrix was heterogeneous in texture, containing small detrital grains of non-phyllosilicate minerals in a fine-grained matrix of $I / S$ clay. The initial observed effect of thermal metamorphism is delamination of phyllosilicates, presumably in response to dehydroxylation. This is shown clearly in BSE images by splitting along layers and in TEM images by rolling and curling of layers. The TEM images imply that delamination progresses into the crystal one layer at a time, SAED patterns showing that the structure of the unaltered portion of the crystal remains intact.

At slightly higher temperatures than those corresponding to dehydroxylation, some quartz inverts to higher temperature polymorphs and the matrix acquires a more homogeneous appearance as grain boundaries within the phyllosilicate groundmass coalesce. Pore space increases as the altered phases contract. Mullite is observed to occur in random orientation within altered clays. At higher temperatures, the altered clay matrix is disordered, as indicated by lack of peaks in XRD and SAED patterns. At the highest non-melt temperatures, detrital, non-phyllosilicate grains begin to react with the altered clay matrix. Silica grains incorporate $\mathrm{Al}$ at interfaces with the reacted clay matrix with concomitant enrichment of $\mathrm{Si}$ in the amorphous matrix material. The clinker is enriched in spinel minerals at contacts with paralava and at cracks where no melt is present. This is most noticeable in BSE images as the size and number of the high contrast phases increase in proximity to cracks and paralava. The increase in abundance of oxides is reflected in increases in $\mathrm{Fe}, \mathrm{Mg}$ and $\mathrm{Mn}$. Concentrations of these elements are also enhanced in the paralava. The high iron content of the paralava is reflected mineralogically in symplectic intergrowths of $\mathrm{Fe}-\mathrm{Ti}-\mathrm{Al}$ oxides and silica within the glassy matrix. Because those phases were observed within the matrix but near the paralava boundary, the symplectites are inferred to be at least in part a residuum of the clinker.

\section{Reactions within clay domains}

The observed early-stage alteration (delamination) is due to dehydroxylation of fine-grained matrix minerals, such as kaolinite, which has been reported to dehydroxylate at approximately $500^{\circ} \mathrm{C}$ (Brindley and Nakahira 1959), illite, which dehydroxylates at $550-600^{\circ} \mathrm{C}$ (Deer et al. 1966), and muscovite, which dehydroxylates at approximately $600^{\circ} \mathrm{C}$ (Vedder and Wilkins 1969). Guggenheim et al. (1987) defined the mechanism for dehydroxylation of muscovite, noting that as $\mathrm{OH}$ diffuses out of the structure, the crystal as a whole is only moderately distorted and may form an intermediate dehydroxylated phase (Brindley and Nakahira 1959; Guggenheim et al. 1987). The structure of illite is retained to at least $1000^{\circ} \mathrm{C}$ during dehydroxylation (Furlong 1967). As consistent with such relations, we have observed peaks of $2: 1$ phyllosilicates in SAED patterns up to the point where the growth of mullite is extensive.

Mullite is known to grow through solid-state reactions from a number of clay minerals upon heating, including pyrophyllite (Heller 1962), kaolinite (Brindley and Nakahira 1959; Comer 1960), muscovite (Grapes 1986), and phengite (Worden et al. 1987). Growth is inferred to be through the solid state in the rocks of this study because, as shown in Fig. 6, mullite was first observed in altered $\mathrm{I} / \mathrm{S}$ which retained a layered structure and enough of the original structure to give peaks in SAED patterns of a $2: 1$ phyllosilicate. However, where none of the original layered strcuture cold be observed, the altered clay matrix gave no diffraction pattern. The STEM EDX analyses demonstrate enrichment of degraded clay in Si relative to $\mathrm{Al}$, as consistent with the loss of Al to mullite as compared with $\mathrm{I} / \mathrm{S}$.

According to Brearley (1986), the random nucleation and growth of mullite can be viewed as a product of a supersaturated solution, where numerous crystallites form at imperfections in the crystal that are thermodynamically favorable. It appears that the mullite is a product of growth within the clay matrix by diffusion of $\mathrm{Al}$ and $\mathrm{Si}$ over distances of less than $500 \mathrm{~nm}$. Such an 
intragrain diffusion mechanism is similar to that of Worden et al. (1987), except they observed that the reaction products grew in a topotactic manner with respect to the host phase, whereas in this study, growth was observed to occur with random orientations.

\section{Intergrain reactions}

Intergrain diffusion became the dominant process at near-melt conditions, as suggested by a decrease in the size of detrital grains, rounding of their angular boundaries, and reaction rims on detrital silica grains as shown in Fig. 7, coupled with the production of pore space. $\mathrm{K}$-feldspar was no longer present in sample KM5, apparently having reacted completely with the matrix material.

In pelitic xenoliths studied by Grapes (1986), the quartz-plagioclase contacts were the first to exhibit evidence of melting. In experimental systems, quartz-feldspar and quartz-mica-feldspar contacts served as sites for initial melt production (Weill and Kudo 1968; Busch et al. 1974). Brearley and Rubie (1990) observed initial melt formation at $\mathrm{K}$-feldspar-muscovite interfaces of quartz-muscovite schist under $\mathrm{H}_{2} \mathrm{O}$-undersaturated conditions.

In this study, a heterogeneous matrix consisting of mullite-rich, non-crystalline degraded-clay was observed to have formed, apparently through solid-state reactions. This altered clay matrix is heterogeneous, in part because of local reactions with silica and K-feldspar or at silica/K-feldspar contacts. Due to the fact that the altered clay matrix is non-crystalline, and because a locally produced melt may cool to a glass as in the case of paralava, we cannot be sure that melt was not a component of the clinker near the paralava interface, as in Figs. 7, 8, and 10. Indeed, the absence of K-feldspar near the paralava implies that it had entirely reacted with the altered I/S matrix. It is difficult to envision such as reaction as occurring without intervention of (and perhaps the first formation of) a melt. However, continuity between the textural relations for the altered I/S matrix and the lack of discontinuities in the composition and texture of the clinker matrix imply that melt was not present in the clinker. Cosca et al. (1989) pointed out that the near-anhydrous metamorphic conditions should give rise to the highest possible minimum melt temperatures. Such anhydrous conditions are represented in this study by the observed dehydroxylation of clay minerals coupled with a loss of nearly all $\mathrm{H}_{2} \mathrm{O}$ between samples KM3 and KM4. Indeed, it is the nearly complete lack of $\mathrm{H}_{2} \mathrm{O}$ that differentiates melt conditions for these rocks from those of other studies. A composition corresponding to a minimum melt temperature must have formed through diffusion in altered $\mathrm{I} / \mathrm{S}$ and at reaction boundaries with detrital minerals at many sites in such a continuously heterogeneous material.

The only unequivocal evidence for the prior existence of a melt, as observed in this study, was obtained for the paralava. The paralava-clinker boundary appears to be relatively sharp. As noted above, the paralava appears to contain some spinel and silica that represents a residuum of the clinker. The paralava melt therefore appears to have been produced along a relatively well-defined interface through reaction of altered clay matrix, $\mathrm{K}$-feldspar, and silica. It is likely that minimum-melt temperatures were produced locally within the clinker, perhaps involving altered $\mathrm{I} / \mathrm{S}$ and $\mathrm{K}$-feldspar reactions as the clinker-paralava interface was approached. Indeed, as shown, for example, by the liquidus of the system $\mathrm{Ca}$ $\mathrm{Al}_{2} \mathrm{Si}_{2} \mathrm{O}_{6}-\mathrm{KAlSi}_{3} \mathrm{O}_{8}-\mathrm{SiO}_{2}$ (Schairer and Bowen 1947), I/S that has been enriched in Si by loss of $\mathrm{Al}$ to mullite $+\mathrm{SiO}_{2}+\mathrm{K}$-feldspar corresponds approximately to minimum-melt temperatures.

The chemical flux occurring during the melt reaction can be determined by comparing the shale composition with that of the paralava. Using the average analysis for KM1-3 and the paralava of Table 1, and assuming the amount of Al remains constant, the following reaction values were calculated, with numbers in terms of atoms per $\mathrm{Al}$ atom.

Host rock +3.04 Fe+0.08 $\mathrm{Mn}+0.23 \mathrm{Mg}+0.25 \mathrm{Ca}-$ $0.25 \mathrm{Si}-0.001 \mathrm{Ti}-0.054 \mathrm{~K}=$ paralava

Cosca et al. (1989; personal communication) noted that the increased $\mathrm{Fe}, \mathrm{Mn}, \mathrm{Mg}$, and $\mathrm{Ca}$ may have been derived from carbonate-rich iron nodules in beds separate from the paralava, those elements having higher concentrations in the nodules. In terms of mineral species, the overall reaction can be approximated by the relation

silica $+\mathrm{K}$-feldspar $+\mathrm{S} / \mathrm{I}+\mathrm{Fe}+\mathrm{Mg}+\mathrm{Ca}+\mathrm{Mn}=$ paralava.

\section{Iron enrichment in paralava}

The mechanism of $\mathrm{Fe}$ addition (as well as $\mathrm{Ca}, \mathrm{Mg}$ and $\mathrm{Mn})$ to the paralava has been addressed in several combustion metamorphic studies. Hypotheses are: (1) original compositional differences; (2) liquid immiscibility; (3) transport of elements in the vapor phase.

In sedimentary horizons where ferruginous nodules are present, local concentrations of $\mathrm{Fe}$ in the fused equivalent of that rock could result from melting of the nodules. Jackson (1981) identified such nodules in the same stratum as the clinker and concluded that since Fe-rich material has a lower melting point with respect to the surrounding material, a melt pod within an area of unmelted clinker could result. The unaltered rocks in the studied horizon, however, were not observed to contain ferruginous nodules or Fe-rich heterogeneities which would give rise to an Fe-rich melt.

Formation of immiscible liquid during partial melting is another postulated mechanism for Fe enrichment in paralava (Cosca et al. 1989). This process would resemble that of the formation of Fe-rich silicate melts. In fact, the composition of the paralava in this study is consistent with these types of naturally and experimentally produced glasses (Bentor et al. 1981; Naslund 1983; Bentor 1984). This method of Fe enrichment requires a complementary $\mathrm{Fe}$-depleted region. In the case of paralava, which is connected to other areas with liquids 
of unknown composition, liquid immisciblity indeed may be a viable mechanism in the enrichment of Fe. In the case of the single paralava pods completely enclosed in clinker, as observed in this study, an Fe-poor liquid should have been directly associated with the pod and be relatively easy to detect. Serial sectioning of a sample into parallel slabs did not reveal an. Fe-poor region. No significant gradients in Fe content were detected in extensive EDS analyses of paralava. Liquid immiscibility is, therefore, ruled out as an Fe-enrichment mechanism in the paralava pods enclosed within clinker and, possibly, in the paralava as a whole.

In some of the earliest studies of clinker/paralava genesis, chloride complexing of $\mathrm{Fe}$ in the vapor phase has been suggested as a mechanism of $\mathrm{Fe}$ enrichment (Rogers 1918). According to Raask (1985), chloride phases present in coal seams are among the first to decompose upon combustion. Hydrochloric acid evolves at temperatures of about $325^{\circ} \mathrm{C}$, following by the volatilization of $\mathrm{Na}$ and $\mathrm{Ca}$ chlorides. As the rising gases pass through $\mathrm{Fe}$-rich phases in the overlying strata, $\mathrm{Cl}$ is inferred to complex with $\mathrm{Fe}$ as well as other elements. Hooper (1982) postulated that when a high temperature region such as a vent is encountered, the complex becomes unstable and $\mathrm{Fe}$ oxides are deposited. Whitney et al. (1985) invoked a similar vapor transport mechanism to explain the high concentration of $\mathrm{Fe}$ in skarns and related deposits associated with mineralized granitic stocks. In that system, chlorides volatilize upon crystallization of a magma. The resulting fluids arc hypothesized to leach Fe from the surrounding rocks as the vapor rises. Iron enrichment occurs, often distant from the source, as the complexes release Fe upon breakdown.

In the present study, vapor transport (possibly accomplished by chloride complexing) is suggested as the mechanism for the Fe enrichment of the high temperature clinker and the paralava itself. Supportive of this hypothesis are the numcrous spinels located in the highest temperature clinker, which grew with no intervention of a liquid phase. Transport of elements such as Fe, $\mathrm{Mg}, \mathrm{Mn}$ and $\mathrm{Ca}$ from layers lower in the sedimentary sequence (possibly those containing ferruginous nodules) into the overlying strata must have occurred via the vapor phase.

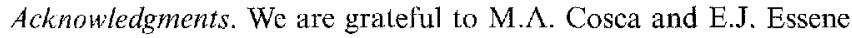
for bringing this project to our attention and for providing the samples used in this study. R.J. Arculus provided assistance with XRF analyses and suggested improvements to the manuscript. The imanuscript was much improved through the reviews of A.J. Brearley, G.D. Guthrie, and J.M. Ferry. We thank the staff of the University of Michigan Microbeam Analysis Laboratory for assistance in the use of the EM facilitics. This research was supported by NSF Grants EAR-8604170 and EAR-8817080 to D.R. Peacor. The JEOL $100 \mathrm{CX}$ analytical STEM used in this study was acquired under NSF Grant No. DMR-77-09643 and the Hatachi S-570 SEM under NSF Grant No. BSR-83-14092.
\end{abstract}

\section{References}

Allen JA (1874) Metamorphism produced by the burning of lignite beds in Dakota and Montana Territories. Boston Soc Nat Hist Proc 16:246-262
Baker G (1953) Naturally fused coal ash from Leigh Creek, South Australia. Trans R Soc Aust 76:1-20

Bastin ES (1905) Note on baked clay and natural slags in eastern Wyoming. J Geol 13:408-412

Bentor YK (1984) Combustion - metamorphic glasses. J NonCryst Solids 67:433-448

Bentor YK, Kastner M, Yellin Y (1981) Combustion metamorphism of bituminous sediments and the formation of melts of granitic and sedimentary composition. Geochim Cosmochim Acta 45:2229-2255

Brcarley AJ (1986) An electron optical study of muscovite breakdown in pelitic xenoliths during pyrometamorphism. Mineral Mag 50:385-397

Brearley A.J (1987) A natural example of the disequilibrium breakdown of biotite at high temperature: TEM observations and comparison with expcrimental kinetic data. Mineral Mag 51:93-106

Brearley AJ, Rubie DC (1990) Effects of $\mathrm{H}_{2} \mathrm{O}$ on the disequilibrium brcakdown of muscovite + quartz. J Petrol 31:925-956

Brindley GW, Nakahira M (1959) The kaolinite-mullite reaction series: II, meta kaolin. J Am Ceram Soc 42[7]:314-318

Busch W, Schneider G, Mehnert KR (1974) Initial melting at grain boundaries: intermediate composition rocks. Neues Jahrb Mineral Monatsh 8:345-370

Cameron WE (1977) Composition and cell dimensions of mullite. Ccram Bull 56[11]:1003-1011

Comer JJ (1960) Electron microscope studies of mullilte development in fired kaolinites. J Am Ceram Soc 43[7]:375-384

Cosca MA, Essene EJ (1985) Paralava chemistry and conditions of formation, Powder River Basin, Wyoming. EOS-Trans Am Geophys Union 66:396

Cosca MA, Essene EJ, Geissman JW, Simmons WB, Coates DA (1989) Pyrometamorphic rocks associated with naturally burned coal beds, Powder River Basin, Wyoming. Am Mineral $74: 85-100$

Deer WA, Howie RA, Zussman J (1966) An introduction to the rock-forming minerals. Longman, London

Furlong RB (1967) Electron diffraction and micrographic study of the high-temperature changes in illite and montmorillonite under continuous heating conditions. Proc Clays Clay Miner 15th Conf, Pergamon Press, New York, pp 87-101

Grapes RH (1986) Melting and thermal reconstitution of pelitic xenoliths, Wehr Volcano, East Eifel, West Germany. J Petrol 27:343-396

Guggenheim S, Chang Y, Koster van Groos AF (1987) Muscovite dehydroxylation: bigh-temperature studies. Am Mineral $72: 537-550$

Heller L (1962) The thermal transformation of pyrophyllite to mullite. Am Mineral 47:156-157

Herring JR (1980) Geochemistry of clinker, naturally burning coal, and mine fires. In: Symposium on the geology of Rocky Mountain coal 80-1:pp 41-44

Hooper RL (1982) Mineralogy of a coal burn near Kemmerer, Wyoming. MS Thesis, Washington State University, Pullman, Washington

Hower J, Eslinger EV, Hower ME, Pcrry EA (1976) Mechanism of burial metamorphism of argillaceous sediments, 1 : mineralogical and chemical cvidence. Geol Soc Am Bull 87:725-737

Jackson KC (1981) Clinker genesis and the comparison of naturally occurring clinker to compounds in the system $\mathrm{FcO}-\mathrm{Al}_{2} \mathrm{O}_{3}-$ $\mathrm{SiO}_{2}$. BS Thesis, Beloit College, Beloit, Wisconsin

Lee JH, Ahn JH, Peacor DR (1985) Textures in layered silicates: progressive changes through diagenesis and low-temperature metamorphism. J Sediment Petrol 55:532-540

Matthews A, Gross S (1980) Petrologic cvolution of the "Mottled Zone" (Hatrurim) metamorphic complex of Israel. Isr J Earth Sci 29:93-106

Naslund HR (1983) The effect of oxygen fugacity on liquid immiscibility in iron-bearing silicate melts. Am J Sci 283:10341059 
Norrish K, Hutton JT (1969) An accurate X-ray spectrographic method for the analysis of a wide range of geological samples. Geochim Cosmochim Acta 33:431-453

Raask E (1985) Mineral impurities in coal combustion: behavior, problems and remedial measures. Hemisphere Publishing Corporation, Washington, DC

Rogers GS (1918) Baked shale and slag formed by the burning of coal beds. USGS Prof Pap 108-A:pp 1-10

Schairer JF, Bowen NL (1947) The system leucite-anorthitesilica. Geol Soc Finland Bull 20:67-87

Smith DGW (1969) Pyrometamorphism of phyllites by a dolerite plug. J Petrol 10:20-55

van der Pluijm BA, Lee JH, Peacor DR (1988) Analytical electron microscopy and the problem of potassium diffusion. Clays Clay Miner 36:498-504

Vedder W, Wilkins RWT (1969) Dehydroxylation and rehydroxylation, oxidation and reduction of micas. Am Mineral 54:482 509
Weill DF, Kudo AH (1968) Initial melting in alkali feldspar-plagioclase-quartz systems. Geol Mag 105:325-337

Whitney JA, Hemley JJ, Simon FO (1985) The concentration of iron in chloride solutions equilibrated with synthetic granitic compositions: the sulfur-free system. Econ Geol 80:444-460

Whitworth HF (1958) The occurrence of some fused sedimentary rocks at Ravensworth, NSW. J Proc R Soc NSW 91-92:204208

Wirth R (1985) Dehydration and thermal alteration of white micas (phengite) in the contact aureole of the Traversella Intrusion. Neues Jahrb Mineral Abh 152[1]: 101-112

Worden RH, Champness PE, Droop GTR (1987) Transmission electron microscopy of the pyrometamorphic breakdown of phengite and chlorite. Mincral Mag 51:107-121

Editorial responsibility: J Ferry 